\title{
Pemberdayaan Masyarakat Melalui Pelatihan Kader Posyandu Remaja Uswatun Hasanah Desa Cikunir
}

\author{
Santi Susanti, Hapi Apriasih, Tupriliany Danefi \\ Program Studi Kebidanan STIKes Respati Tasikmalaya \\ Email: santiazhari@gmail.com, HP 085221547890)
}

\begin{abstract}
Abstrak
Masa remaja merupakan masa storm and stress, karena remaja mengalami banyak tantangan baik dari diri mereka sendiri (biopsychosocial factors) ataupun lingkungan (environmental factors). Apabila remaja tidak memiliki kemampuan untuk menghadapi berbagai tantangan tersebut, mereka dapat berakhir pada berbagai masalah kesehatan yang begitu kompleks sebagai akibat dari perilaku berisiko yang mereka lakukan. Melalui focus grup discucion (FGD) diperoleh informasi dari 35 responden remaja sebagai berikut $48,7 \%$ belum mengetahui tentang kesehatan reproduksi khususnya terkait infeksi menular seksual, 45,71\% sudah mempunyai pacar. Tujuan kegiatan ini adalah untuk membentuk kader posyandu remaja di Desa Cikunir wilayah kerja puskesmas Singaaparna Kabupten Tasikmlaya tahun 2019. Melalui program ini manfaat untuk Desa Cikunir akan mendapatkan sumber daya manusia yang kompeten dalam menyelenggarakan posyandu remaja di wilayah desa. Metode dalam program pengabdian masyarakat menggunakan metode eskperimen dengan metode one group pretest posttest. Pretest pertama dilakukan untuk mengukur pengetahuan kader remaja tentang posyandu remaja, kesehaatan reproduksi, gizi pada remaja dan IMS-HIV/AIDS. Kemudian para kader mendapatkan pelatihan terkait materi posyandu remaja selama 2 hari. Postest dilakukan setelah kegiatan pelatihan selesai. Hasil analisis data ditemukan perbedaan rata-rata skor pengetahuan sebelum dengan setelah pelatihan kader dilaksanakan. Uji bivariate menunjukkan $p<0,05$ artinya terdapat perbedaan pengetahuan sebelum diberikan pelatihan dengan pengetahuan subyek setelah diberikan pelatihan. Kesimpulan melalui pelatihan kader remaja mampu meningkatkan perubahan pengetahuan kader posyandu remaja. Kepada ketua kelompok kerja posyandu untuk dapat meningkatkan program pembinaan kader posyandu remaja melalui pendidikan dan pelatihan yang rutin dan berkelanjutan. Kepada Puskesmas disarankan untuk membina dan melakukan pemantauan posyandu sehingga mampu membentuk posyandu remaja yang mandiri
\end{abstract}

Kata Kunci : Posyandu, Remaja, Pengetahuan

\begin{abstract}
Adolescence is a time of storm and stress, because adolescents experience many challenges both from themselves (biopsychosocial factors) or the environment (environmental factors). If adolescents do not have the ability to face these challenges, they can end up in various complex health problems as a result of the risky behavior they do. Through a focus group discussion (FGD), information was obtained from 35 adolescent respondents as follows: 48.7\% did not know about reproductive health, especially related to sexually transmitted infections, $45.71 \%$ had a boyfriend. The purpose of this activity is to form youth Posyandu cadres in Cikunir Village, the working area of the Singaparna Community Health Center, Tasikmalaya Regency in 2019. Through this program, the benefits of Cikunir Village will be to get competent human resources in organizing youth Posyandu in the village area. The method
\end{abstract}


in the community service program uses the experimental method with the one group pretest posttest method. The first pretest was carried out to measure the knowledge of youth cadres about youth Posyandu, reproductive health, nutrition for adolescents and STI-HIV / AIDS. Then the cadres received training related to youth Posyandu material for 2 days. The posttest is carried out after the training is complete. The results of data analysis found a difference in the average score of knowledge before and after the cadre training was carried out. The bivariate test showed $p<0.05$, meaning that there was a difference in knowledge before being given training with the knowledge of the subject after being given training. The conclusion is that through youth cadre training, it is able to increase the change in knowledge of youth posyandu cadres. To the head of the posyandu working group to be able to improve the youth Posyandu cadre development program through regular and ongoing education and training. Puskesmas are advised to guide and monitor posyandu so that they can form an independent youth Posyandu

Keywords: Posyandu, Youth, Knowledge

\section{PENDAHULUAN}

Masa remaja merupakan masa storm and stress, karena remaja mengalami banyak tantangan baik dari diri mereka sendiri (biopsychosocial factors) ataupun lingkungan (environmental factors). Apabila remaja tidak memiliki kemampuan untuk menghadapi berbagai tantangan tersebut, mereka dapat berakhir pada berbagai masalah kesehatan yang begitu kompleks sebagai akibat dari perilaku berisiko yang mereka lakukan.

Berdasarkan hasil Survei Kesehatan Berbasis Sekolah di Indonesia tahun 2015 (GSHS) dapat terlihat gambaran faktor risiko kesehatan pada pelajar usia 12-18 tahun (SMP dan SMA) secara nasional. Sebanyak 41,8\% laki-laki dan 4,1\% perempuan mengaku pernah merokok, $32,82 \%$ di antara merokok pertama kali pada umur $\leq 13$ tahun. Data yang sama juga menunjukkan $14,4 \%$ laki-laki dan 5,6\% perempuan pernah mengkonsumsi alkohol, lalu juga didapatkan 2,6\% laki-laki pernah mengkonsumsi narkoba. Gambaran faktor risiko kesehatan lainnya adalah perilaku seksual di mana didapatkan 8,26\% pelajar laki-laki dan 4,17\% pelajar perempuan usia 12-18 tahun pernah melakukan hubungan seksual.

Perilaku seks pranikah tentunya memberikan dampak yang luas pada remaja terutama berkaitan dengan penularan penyakit menular dan kehamilan tidak diinginkan serta aborsi. Kehamilan pada remaja tidak hanya berpengaruh terhadap kondisi fisik, mental dan sosial remaja, tetapi juga dapat meningkatkan risiko kematian bayi/balita, seperti yang ditunjukkan SDKI 2012 di mana kehamilan dan persalinan pada ibu di bawah umur 20 tahun memiliki kontribusi dalam tingginya Neonatal Mortality Rate (34/1000 KH), Postnatal Mortality Rate (16/1000 KH), Infant Mortality Rate (50/1000 KH) dan Under-5 Mortality Rate (61/1000 KH). Laporan triwulan Direktorat Jenderal Pengendalian Penyakit dan Penyehatan Lingkungan (Ditjen P2PL) mulai 1987 sampai dengan Maret 2017 menunjukan bahwa tinginya angka kejadian AIDS di kelompok usia 20-29 tahun mengindikasikan kelompok tersebut pertama kali terkena HIV pada usia remaja.

Kompleksnya permasalahan kesehatan pada remaja, tentunya memerlukan penanganan yang komprehensif dan terintegrasi yang melibatkan semua unsur dari lintas program dan sektor terkait. Kebijakan bidang kesehatan terkait pelayanan kesehatan remaja sebagaimana dimaksud Permenkes Nomor 25 Tahun 2014 ditujukan agar setiap anak memiliki kemampuan berperilaku hidup bersih dan sehat, memiliki keterampilan hidup sehat, dan keterampilan sosial yang baik sehingga dapat belajar, tumbuh dan berkembang secara harmonis dan optimal menjadi sumber daya manusia yang berkualitas. 
Desa Cikunir merupakan desa di wilayah Puskesmas Singaparna yang terdiri atas tiga dusun yaitu Gunung kawung, Pameungpeuk, dan Anggaraja. Melalui kegiatan Praktek Kerja Nyata mahasiswa program studi kebidanan STIKes Respati melalui focus group discussion (FGD) diperoleh informasi dari 35 responden remaja sebagai berikut $48,7 \%$ belum mengetahui tentang kesehatan reproduksi khususnya terkait infeksi menular seksual, 45,71\% sudah mempunyai pacar, 51,43\% tidak mengetahui tentang HIV/AIDS, 22,86\% tidak mengetahui dampak pernikahan dini, dan $11,43 \%$ setuju dengan pernikahan dini. Informasi lain yang ditemukan adalah bahwa sumber informasi kesehatan reproduksi 29 orang menjawab guru, 4 orang dari televisi, 7 orang dari internet, 1 orang dari orang tua, 1 orang dari teman, dan hanya 5 orang dari tenaga kesehatan.

Berdasarkan data tersebut diketahui bahwa pengetahuan remaja tentang kesehatan reproduksi masih kurang. Kurangnya pengetahuan remaja akan berdampak pada permasalahan serius. Oleh karena itu maka menjadi hal yang sangat penting untuk membentuk sebuah wadah pemberdayaan masyarakat dalam memberikan tempat untuk para remaja memeriksakan diri dan berkonsultasi terkait kesehatan. Posyandu remaja merupakan salah satu bentuk upaya kesehatan bersumber daya masyarakat (UKBM) yang dikelola dan diselenggarakan dari, oleh, untuk dan bersama masyarakat termasuk remaja dalam penyelenggaraan pembangunan kesehatan.

Dalam penyelenggaraan posyandu remaja diperlukan pengelola posyandu dalam hal ini kader. Oleh karena hal tersebut, maka diperlukan pembentukan dan pelatihan kader untuk mempersiapkan sumber daya manusia yang kompeten dalam penyelenggaraannya. Tujuan kegiatan ini adalah untuk membentuk kader posyandu remaja di Desa Cikunir wilayah kerja puskesmas Singaparna Kabupaten Tasikmalaya tahun 2019. Melalui program ini manfaat untuk Desa Cikunir akan mendapatkan sumber daya manusia yang kompeten dalam menyelenggarakan posyandu remaja di wilayah desa.

\section{BAHAN DAN METODE}

Metode dalam program pengabdian masyarakat menggunakan metode eskperimen dengan metode one group pretest posttest. Pretest pertama dilakukan untuk mengukur pengetahuan kader remaja tentang posyandu remaja, kesehaatan reproduksi, gizi pada remaja dan IMS-HIV/AIDS. Kemudian para kader mendapatkan pelatihan terkait materi posyandu remaja selama 2 hari. Postest dilakukan setelah kegiatan pelatihan selesai. Program dilaksanakan di kampus STIKes Respati Tasikmalaya pada hari Kamis tanggal 7 Maret 2019 dan hari Sabtu tanggal 9 Maret 2019. Populasi adalah seluruh kader posyandu remaja uswatun hasanah desa Cikunir. Tekhnik pengambilan sampel menggunakan total sampling berjumlah 10 orang kader.

Tekhnik pengumpulan data dilaksanakan pada hari pertama pelatihan seluruh kader diberikan test. Kemudian perlakuan didapatkan oleh seruluh sampel dengan mengikuti pelatihan selama 2 hari dengan menghadirkan narasumber dari puskesmas singaparna, dosen prodi kebidanan STIKes Respati dan psikolog. Post test diberikan kepada seluruh peserta pada hari terakhir pelatihan. Analisis data menggunakan uji $\mathrm{T}$ test untuk mengukur tingkat perbedaan pengetahuan kader sebelum dilaksanakan pelatihan dengan setelah dilaksnakan pelatihan.

\section{HASIL}

Karakteristik subyek penelitian bedasarkan tingkat pendidikan $80 \%$ kader adalah masih aktif sekolah dengan distribusi frekuensi sebagai berikut $60 \%$ tingkat pendidikan adalah SMP, 
$20 \%$ dengan tingkat pendidikan SMA dan 20\% sudah lulus SMA. Karakteristik berdasarkan umur sebagian besar responden berada pada usia remaja tengah (14 - 16 tahun) yaitu 60\%. Hasil analisis data ditemukan perbedaan rata-rata skor pengetahuan sebelum dengan setelah pelatihan kader dilaksanakan. Uji bivariate menunjukkan $p<0,05$ artinya terdapat perbedaan pengetahuan sebelum diberikan pelatihan dengan pengetahuan subyek setelah diberikan pelatihan.

\section{PEMBAHASAN}

Berdasarkan hasil tersebut maka pelatihan kader remaja berkontribusi terhadap peningkatan pengetahuan remaja dalam menguasai materi penyelenggaraan posyandu remaja. Pengetahuan yang baik akan memberikan kesadaran dalam berperilaku sehat serta keaktifan kader dalam menyelenggarakan kegiatan posyandu baik persiapan sebelum, pada saat dan setelah kegiatan Posyandu berlangsung. Jika dalam kegiatan posyandu ditemukan masalah kesehatan, kader dapat segera merujuk kepada pelayanan kesehatan terdekat atau Puskesmas (Ida dkk, 2017). Hal ini sejalan dengan penelitian yang dilakukan oleh Sukiarko (2007) dengan hasilnya bahwa pelatihan dengan metode BBM lebih meningkatkan pengetahuan dan keterampilan kader gizi dalam kegiatan posyandu dibandingkan metode konvensional. Demikian juga hasil penelitian Witdiawati, dkk (2018) Terdapat perbedaan yang bermakna antara pelatihan mengenai pentingnya antenatal care terhadap pengetahuan kader posyandu Desa Gunungtiga.

Posyandu adalah kegiatan kesehatan dasar yang diselenggarakan dari, oleh dan untuk masyarakat yang dibantu oleh petugas kesehatan di suatu wilayah kerja puskesmas. Posyandu merupakan langkah startegis dalam rangka pengembangan kualitas sumber daya manusia agar dapat membangun dan menolong dirinya sendiri, sehingga perlu ditingkatkan pembinannya. Manfaat posyandu bagi masyarakat adalah kemudahan mendapatkan pelayanan kesehatan dasar, memperoleh bantuan dalam pemecahan maalah kesehatan, efisiensi dalam mendapatkan pelayanan terpadu. Selain bagi masyarakat posyandu juga bermanfaaat untuk kader meliputi mendapatkan informasi tentaang upaya kesehatan, serta dapat membantu masyarakat menyelesaikan maslaah kesehatan (Budiman 2015). Kader adalah seorang tenaga sukarela yang direkrut dari, oleh dan untuk masyarakat yang bertugas membantu kelancaran pelayanan kesehatan. Keberadaan kader sering dikaitkan dengan pelayanan rutin di posyandu. Posyandu remaja merupakan salah satu program baru di kementrian kesehatan. Belum banyak remaja yang menjadi kader. Maka dalam penyelenggraan posyandu tersebut perlu dilakukan upaya pemberdayaan remaja melalui pelatihan kader remaja.

Tujuan pemberdayaan masyarakat adalah membantu klien memperoleh kemampuan untuk mengambil keputusan dan menentukan tindakan yang akan ia lakukan yang terkait dengan diri mereka, termasuk mengurangi hambatan pribadi dan hambatan sosial dalam pengambilan tindakan. Pengetahuan merupakan faktor yang mempermudah atau mempredisposisi terjadinya perilaku seseorang. Pengetahuan adalah hasil pengindraan manusia. Pengetahuan seseorang terhadap obyek mempunyai tingkatan yang berbeda meliputi tahu, memahami, aplikasi, analisis, sintesis dan evaluasi. Pemberdayaan masyarakat merupakan serangkaian upaya self efficacy yaitu upaya yang dilakukan dengan memberikan pendidikan kesehatan yag terus menrus menggunakan beberaap metode yang cocok,kombinasi komunikasi massa,komunikasi kelompok dan komunikasi interpersonal, sehingga masyarakat mempunyai kemampuan dan kepercayaan diri untuk mengambil tindakan yang rasional (Notoatmotdjo,2010) Sementara itu Fitriani, S ( 2011) menjelaskan 
pendidikan kesehatan proses perubahan perilaku yang dinamis, merupakan komponen program kesehatan yang isinya erencanaan untuk perubahan perilaku individu,kelompok dan masyarakat sehubungan dengan pencegahan penyakit, penyembuhan penyakit dan pemulihan kesehatan. Tujuan pendidikan kesehatan adalah untuk mengubah perilaku orang atau masyarakat dari perilaku yang tidak sehat atau belum sehat menajdi perilaku sehat. Seseorang dapat dikatakan belajar apabila di dalam dirinya terjadi perubahan dari tidak tahu menjadi tahu atau dari tidak bisa mengerjakan sesuatu menjadi mampu mengerjakan sesuatu. Kegiatan belajar atau pendidikan mempunyai tiga ciri sebagai berikut : (1) Belajar adalah kegiatan yangmampu menghasilkan perubahan pada individu, kelompok atau masyarakat yang sedang belajar baik itu secara actual atau potensial, (2) Perubahan didapatkan karena kemampuan baru yang berlaku dalam relative waktu yang lama, (3) Perubahan yang terjadi karena usaha dan disadari bukan suatu kebetulan.

Metode pendidikan kesehatan pada pelatihan dengan kelompok kecil yaitu peserta kegiatan kurang dari 15 orang dapat dilakukan dengan metode sebagai berikut : (1) Diskusi kelompok, dimana semua anggota kelompok berpartisipasi dalam diskusi, maka formasi duduk peserta diatur sedemikan rupa sehingga mereka dapa berhadap-hadapans atu dengan lainnya, (2) Curah pendapat (brain storming), cara ini dilakukan dengan pemimpin diskusi memancing dengan satu masalah dankemudian tiap peserta memberikan tanggapan (3) Bola Salju (Snow Balling), (4) Kelompok-kelompok kecil (buzz group), (5) Role Play (memainkan peran), dan (6) Permainan simulasi (simulation game) ( Supiyati dan Ambarwati, 2012).

\section{KESIMPULAN DAN SARAN}

Pelatihan kader remaja mampu meningkatkan perubahan pengetahuan kader posyandu remaja. Kepada ketua kelompok kerja posyandu untuk dapat meningkatkan program pembinaan kader posyandu remaja melalui pendidikan dan pelatihan yang rutin dan berkelanjutan. Kepada Puskesmas disarankan untuk membina dan melakukan pemantauan posyandu sehingga mampu membentuk posyandu remaja yang mandiri.

\section{UCAPAN TERIMAKASIH}

Segala puji dan syukur dipanjatkan kepada Aloh SWT atas izin dan ridho-NYA program pelatihan kader posyandu remaja desa Cikunir dapat selesaikan. Program ini dapat terselenggara atas kerjasama dan dukungaan yang baik dari berbagai pihak, oleh karena itu penulis menyampaikan terimakasih kepada : (1) Ketua STIKes Respati Tasikmalaya (2) Kepala Desa Cikunir dan seluruh tokoh masyarakat, (3) Kepala Puskesmas Singaparna beserta seluruh jajarannya, (4) Bidan Desa wilayah Cikunir, (5) Kader posyandu, (6) Mahasiswa kebidanan STIKe Respati. Semoga Alloh SWT meridhoi dan menjadikan berkah untuk seluruh pemegang kepentingan. Aamiin.

\section{DAFTAR PUSTAKA}

Budiman (2015), "Buku Ajar Isu Tataran Kesehatan Masyarakat", Refika Aditama, Bandung Fitriani, S., (2011) Promosi Kesehatan, Graha Ilmu, Yogyakarta

Notoatmodjo.S., 2010, Promosi Kesehatan Teori dan Aplikasi, Rineka Cipta, Jakarta

Sulistyorini.I.C, Pebriyanti.A., Proverawati.A., (2010), Posyandu dan desa siaga, Nuha Medika, Bantul

Supiyati., Ambarwati.R., (2012), Promosi Kesehatan dalam Perspektif IImu Kebidanan, Pustaka Rihama, Yogyakarta 
Sukiarko, E (2007), "Pengaruh Pelatihan Dengan Metode Belajar Berasarkan masalah terhadap pengetahuan danketerapilan kader gizi dalam kegiatan Posyandu (Studi Di Kecamatan Tempuran Kabupaten Magelang)", https://core.ac.uk/download/pdf/11715515.pdf, 3 Juli 2019

Sidqoyie, C (2019). "Perbedaan pengetahuan antara sebelum dan sesudah pelatihan mengenai pentingnya Antenatal care pada kader posyandu di desa gunung tiga Kecamatan Ulubelu Kabupaten Tanggamus Lampung", fakultas kedokeran universitas lampung

http://digilib.unila.ac.id/55340/3/SKRIPSI\%20TANPA\%20BAB\%20PEMBAHASAN.pdf, , 3 Juli 2019

Witdiawati, Sukmawati, Lilis Mamuroh, (2018), "Penguatan Kapasitas Kader Kesehatan dalam Upaya Meningkatkan Dukungan Sosial Berbasis Masyarakat terhadap Klien Kanker Payudara", Fakultas keperawatan Universitas padjadjaran, MKK: Volume 1 No 1 Mei 2018 file:///D:/Downloads/16983-46437-1-PB.pdf, , 3 Juli 2019,

Kementrian Kesehatan RI, 2018, "Petunjuk tekhnis pelaksanaan posyandu remaja", http://kesga.kemkes.go.id/images/pedoman/Petunjuk\%20Teknis\%20Penyelenggara an\%20Posyandu\%20Remaja.pdf, 28 Februari 2019

Ida Untari1, Ratih Prananingrum, Dewi Pertiwi Dyah Kusumadaryati, (2017), "Peningkatan Pengetahuan Dan Keterampilan Kader Dalam Pelayanan Posyandu Balita Melalui Pelatihan Dengan Metode Student Center Learning", Universitas Muhammadiyah Magelang, file://D:/Downloads/1047-Article\%20Text-3505-1-10-20171104.pdf, 7 Juli 2019 